Z. Jabua, A.Gigineishvili, K. Davitadze, T. Minashvili and G. Iluridze

\title{
Preparation and relative mechanical strength of erbium monoselenide films
}

ABSTRACT. For the first time the technology of preparation of thin crystalline films of ErSe has been developed, by vacuum-thermal evaporation from two independent sources of the components and from presynthesized bulk ErSe. The relative mechanical strength of the prepared films was evaluated by complete attrition. It was shown that this strength of films depends on the method of preparation. Films prepared by bulk evaporation have 30-35\% higher mechanical strength than films prepared by evaporation from two independent sources. This may be due to the crystalline structure of the films prepared by bulk evaporation being more perfect.

Nanotechnology Perceptions 15 (2019) 257-259

doi: 10.4024/N28JA19L.ntp.15.03 